\title{
MORFOLOGIA POLÍNICA DE CAPPARIS L. (CAPPARACEAE JUSS.) DE PERNAMBUCO, BRASIL ${ }^{1}$
}

\author{
Maria Bernadete Costa e Silva ${ }^{2}$ \\ Hiroko Makino Watanabe ${ }^{3}$ \\ Margareth Ferreira de Sales ${ }^{2}$
}

Recebido em 21/12/1998. Aceito em 06/05/1999

\begin{abstract}
RESUMO - (Morfologia polínica de Capparis L. (Capparaceae Juss.) de Pernambuco, Brasil). Foram estudados os grãos de pólen de Capparis flexuosa L., C. frondosa Jacq., C. jacobinae Moric ex Eichler e C. yco (Mart.) Eichler, coletados no Estado de Pernambuco, com o objetivo de contribuir para a melhor delimitação das espécies e ampliar o conhecimento da morfologia polínica da família. O material polínico foi acetolisado e os grãos de pólen examinados em microscopia de luz e eletrônica de varredura. As diferenças morfológicas observadas, principalmente quanto à ornamentação da exina, mostram a tendência euripolínica do gênero Capparis.
\end{abstract}

Palavras-chaves - grãos de pólen, morfologia polínica, Capparis, Pernambuco

ABSTRACT - (Pollen morphology of Capparis L. (Capparaceae Juss.) of Pernambuco State, Brazil). Pollen grains of Capparis flexuosa L., C. frondosa Jacq., C. jacobinae Moric ex Eichler and C. yco (Mart.) Eichler, collected in the State of Pernambuco, were studied with the aim of contributing to the best delimitation of the species as well as of extending knowledge on pollen morphology of this family. The pollen material was acetolised and examined at optical and scanning electron microscopy level. The morphological differences observed, especially of exine ornamentation, showed the euripalynous tendency of the genus Capparis.

Key words - pollen grains, pollen morphology, Capparis, Pernambuco State, Brazil

\section{Introdução}

A família Capparaceae Juss. pertence à ordem Capparales e foi dividida por Eichler (1865) em duas tribos: Cappareae e Cleomeae.

O gênero Capparis L., um dos representantes da tribo Cappareae, com aproximadamente 350 espécies, é considerado o maior da família e está distribuído nas regiões tropicais e subtropicais, especialmente da África e das Américas (Jacobs
1960; Willis 1980). No Brasil, ocorrem cerca de 15 espécies em bordas de mata, caatingas e restingas (Barroso et al. 1978). Taxonomicamente, o gênero é complexo e apresenta problemas de delimitação específica envolvendo algumas de suas espécies (Hutchinson 1968; Jacobs 1960), estando bem representado na flora da caatinga de Pernambuco.

Do ponto de vista palinológico, poucos estudos têm sido realizados para o gênero

\footnotetext{
Parte da Dissertação de Mestrado da primeira Autora

2 Departamento de Biologia, Universidade Federal Rural de Pernambuco, Rua Dom Manuel de Medeiros s/n, CEP 52171900, Recife, Pernambuco, Brasil

3 Instituto de Botânica, C. Postal 4005, CEP 01061-970, São Paulo, SP, Brasil
} 
Capparis, destacando-se os trabalhos de Gomes Jr. (1966), Gonçalves-Esteves \& Ferreira (1994), Huang (1972) e Roubik \& Moreno (1991), nos quais foram descritos os grãos de pólen de algumas espécies do gênero.

No presente trabalho estudou-se os grãos de pólen de quatro espécies de Capparis que ocorrem no Estado de Pernambuco, com o objetivo de contribuir para a delimitação taxonômica destas espécies e para ampliar o conhecimento sobre a morfologia polínica da família Capparaceae.

\section{Material e métodos}

Os materiais polínicos foram obtidos a partir de material fresco coletado no campo e fixado em ácido acético glacial, e de material herborizado, depositado no herbário "Prof. Vasconcelos Sobrinho" da Universidade Rural de Pernambuco. Para análise em microscopia de luz, o método utilizado foi o de acetólise (Erdtman 1960) e para microscopia eletrônica de varredura (MEV), o método de Fonnegra (1989), com algumas modificações. As medidas dos diâmetros foram feitas aleatoriamente em 25 grãos de pólen acetolisados, no prazo de uma semana, tendo sido calculadas a média aritmética (x), o desvio padrão da média $\left(\mathrm{s}_{\mathrm{x}}\right)$, o desvio padrão da amostra (s) e o coeficiente de variabilidade (V). Para os demais caracteres polínicos, tomou-se apenas 10 medidas, calculando-se a média aritmética. As fotomicrografias foram obtidas em fotomicroscópio Olympus-Vanox, e as elétron-micrografias, em MEV JEOL-T200.

Para a descrição polínica, a nomenclatura adotada foi a de Barth \& Melhem (1988) e Punt et al. (1994).

Material estudado - Capparis flexuosa (L.) L. BRASIL. Pernambuco: Serra Talhada, Estação Experimental do IPA, 20/XI/1993, Costa e Silva 168 (PEUFR)*; Floresta, Brejo de Serra Negra, 8/I/1997, Nascimento 29 (PEUFR); Inajá, Reserva Bilógica, 9/XII/1995, Laurênio et al. 259 (PEUFR).; C. frondosa Jacq. Pernambuco, Arquipélago de Fernando de Noronha, subida do morro da Conceição, 5/III/1993, Costa e Silva 86 (PEUFR); C. jacobinae Moric ex Eichler:
Pernambuco, Serra Talhada, fazenda Cajuí a caminho de Triunfo, 4/XII/1993, Costa e Silva 180 (PEUFR)*; Buíque, /1966, Figueiredo 227 (PEUFR); Floresta, Refúgio Biológico de Serra Negra, 25/X/1996, Nascimento 15 (PEUFR); $C$. yco (Mart.) Eichler: Pernambuco, Serra Talhada, fazenda Cajuí, $7 \mathrm{~km}$ a caminho de Triunfo, 9/II/ 1993, Costa e Silva 68 (PEUFR)*; Floresta da Reserva Biológica de Serra Negra, 27/VIII/1994, Sales 340 (PEUFR); Inajá (Reserva Municipal), 14/II/1996, Silva 143 (PEUFR).

As exsicatas selecionadas como materialpadrão, no qual foram feitas as medidas e observações necessárias para a caracterização polínica, estão assinaladas por um asterisco (*) na citação do material examinado, sendo as demais exsicatas utilizadas como materiais de comparação.

\section{Resultados}

A análise palinológica das espécies de Capparis estudadas revelou a existência de grãos de pólen pequenos a médios, com âmbito subtriangular a subcircular, subprolatos a prolatos, 3-(4)-colporados; endoabertura lalongada; exina tectada com ornamentação reticulada, microrreticulada, espinhosa ou espiculosa (Tab. 1).

Aberturas - Colpos longos equatorialmente dispostos (Fig. 2, 4, 9, 10, 16, 17, 18, 22 e 23), com terminações arredondadas e larguras variáveis, chegando quase a se unirem nos polos; endoabertura lalongada com contorno impreciso, de difícil mensuração e recoberta por membrana granulosa (Fig. 2, 10,17 e 23). C. jacobinae (Fig. 15-20) possui grãos de pólen pticotremados (ou fossaperturados) (Fig. 15 e 19) e as demais espécies, goniotremados (ou angulaperturados) (Fig. 1, 7, 21 e 24). Em C. frondosa (Fig. 7-14), registrou-se $73 \%$ de grãos de pólen 4-colporados e $27 \%$ de 3 -colporados. Mais raramente foram detectados nesta espécie grãos de pólen com uma das faces pseudofenestrada (Fig. 11 e 13).

Exina - Foram observados dois tipos de ornamentação da exina: o reticulado, com retículos nítidos e maiores em C. jacobinae (Fig. 17-20), e pouco nítidos e menores (microrreticulado) em $C$. 
Tabela 1. Caracterização morfológica dos grãos de pólen de espécies de Capparis $(\mathrm{ST}=$ subtriangular; $\mathrm{SC}=$ subcircular; $\mathrm{P}=$ diâm. polar; $\mathrm{E}=$ diâm. equatorial).

\begin{tabular}{lcccc}
\hline Características & C. flexuosa & E. frondosa & C. jacobinae & C. yco \\
\hline tamanho & pequeno a médio & pequeno a médio & médio & médio \\
forma & subprolata & subprolata & subprolata & subprolata \\
ambito & ST & ST, SC & ST & SC \\
cólporos & 3 & $(3)-4$ & 3 & 3 \\
escultura & espinhosa & espiculosa & reticulada & microrreticulada \\
P/E & 1,32 & 1,22 & 1,19 & 1,20
\end{tabular}

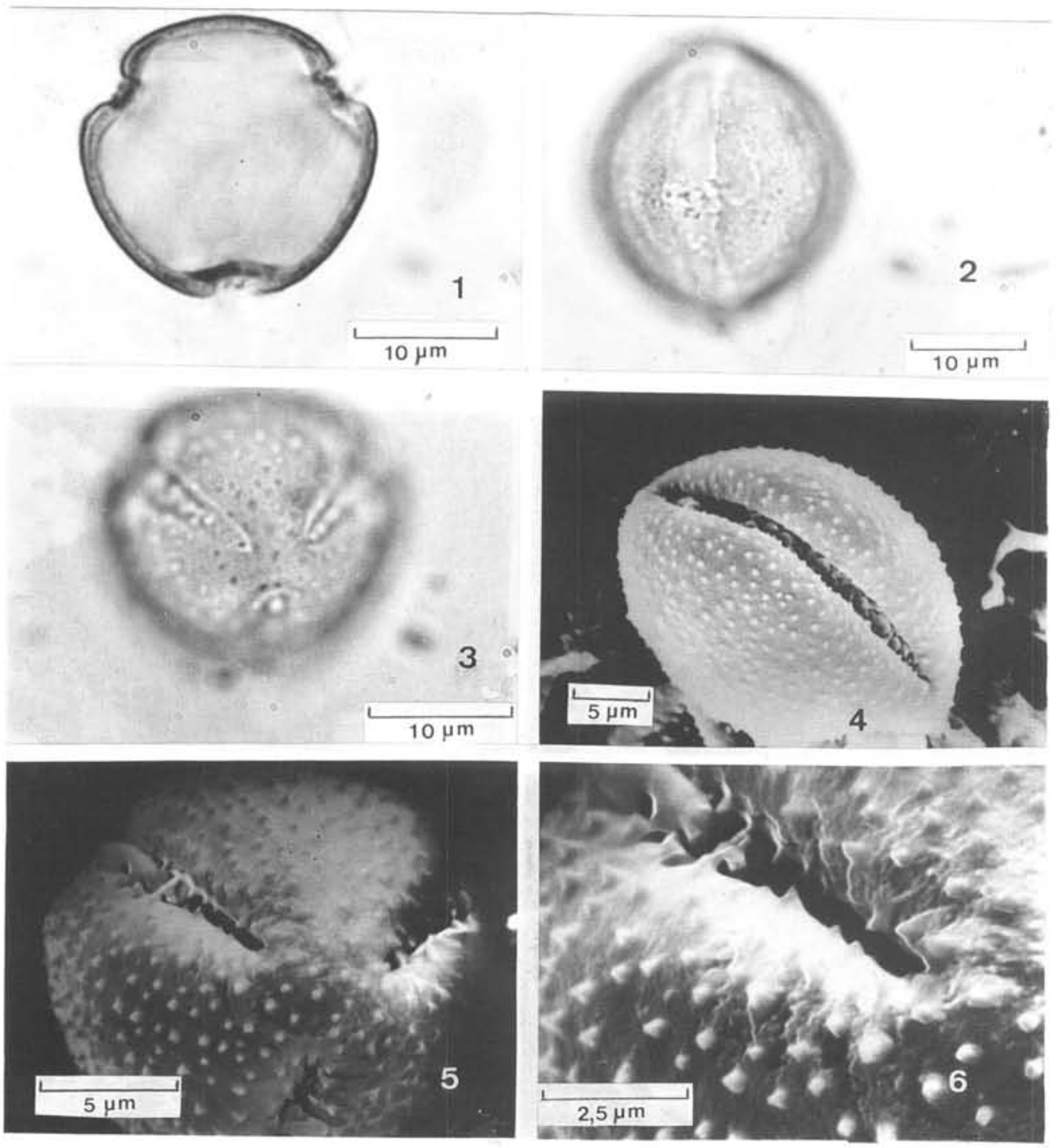

Figuras 1-6. Capparis flexuosa (L.) L. I.Vista polar do grão de pólen, mostrando o contorno e o corte óptico da exina; 2 . Vista equatorial e detalhe da abertura; 3 . Escultura da exina; 4 . Elétron-micrografia do pólen em vista equatorial. 5. Vista polar. 6 . Detalhe
da abertura e escultura da exina. 

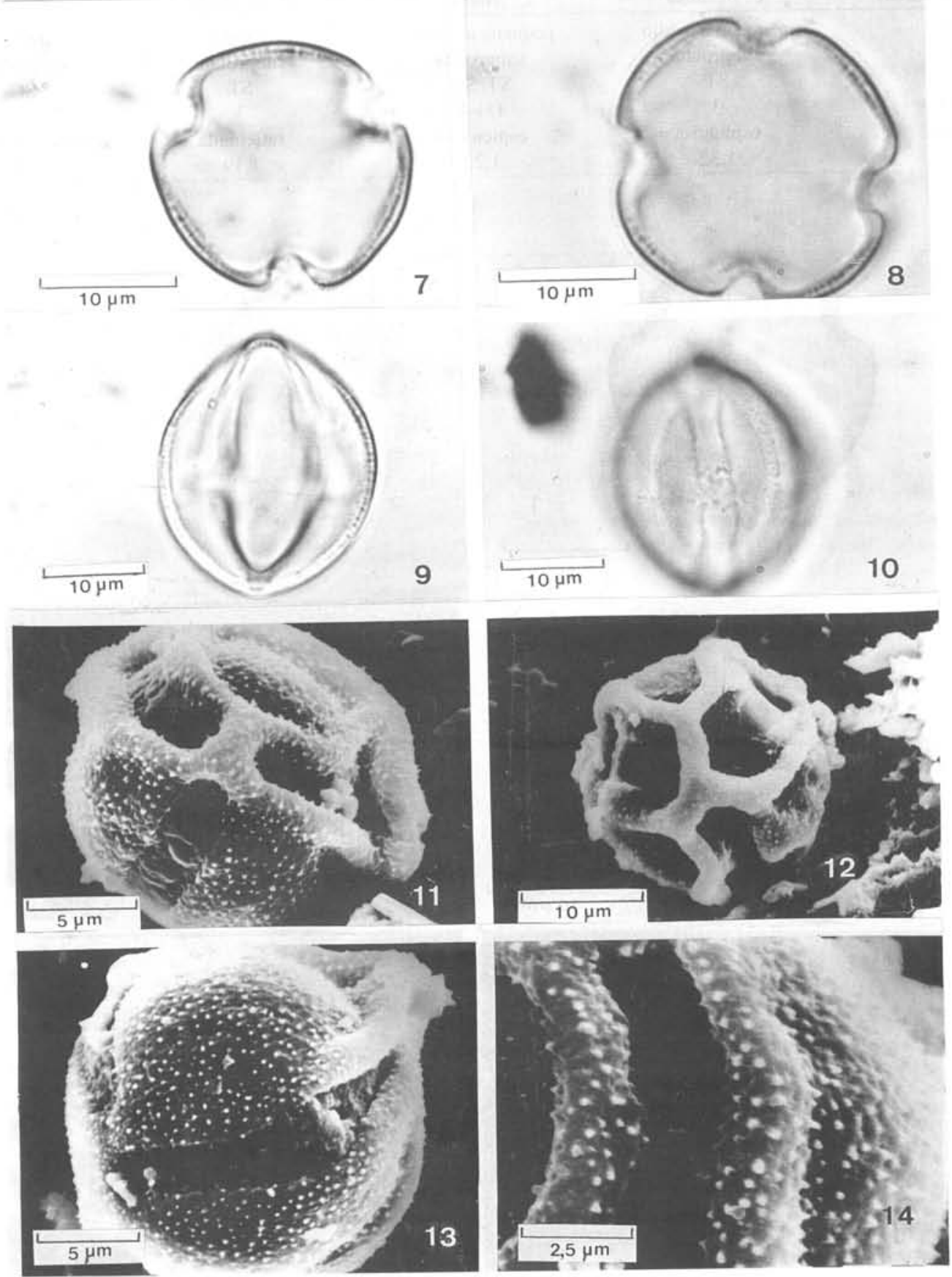

Figuras 7-14. Capparis frondosa Jacq. 7. Vista polar, contorno e corte óptico de um grão de pólen com três aberturas; 8 . Idem, grão de pólen com quatro aberturas; 9 . Vista equatorial; 10. Detalhe da abertura; 11. Elétron-micrografia em vista polar de um grāo de pólen com a morfologia alterada:12. Face pseudofenestrada de um pólen anormal; 13. Detalhe de uma abertura; 14. Detalhe da escultura. 

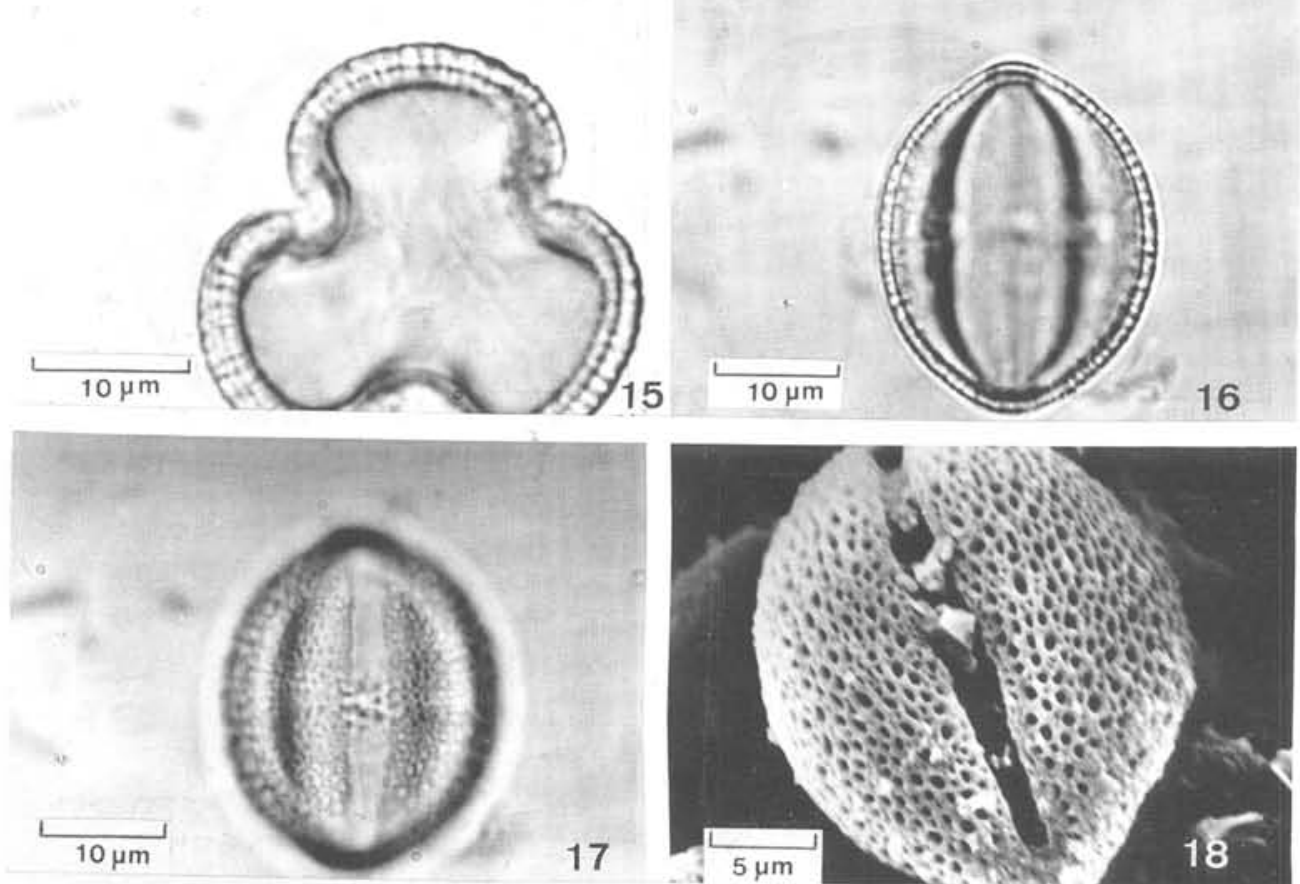

17
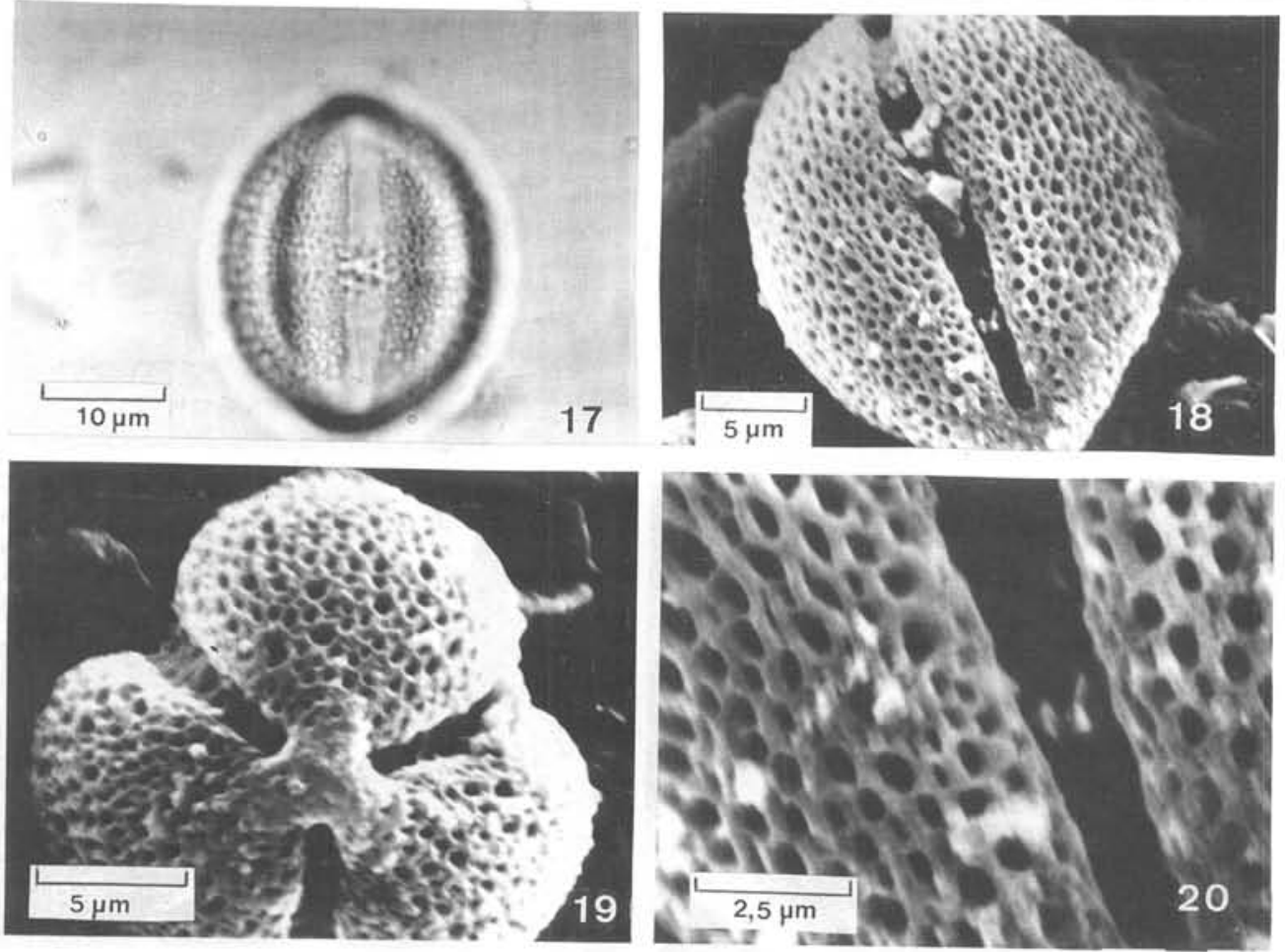

Figuras 15-20. Capparis jacobinae Moric ex Eichler 15. Fotomicrografia do pólen em vista polar mostrando o contorno e corte óptico; 16. Vista equatorial; 17. Detalhe da abertura; 18. Elétron-micrografia do pólen em vista equatorial; 19. Vista polar; 20. Detalhe da superfície do pólen.

yco (Fig. 25-26) e o espinhoso, com espinhos maiores em C. flexuosa (Fig. 3-6) e menores (espiculada) em $C$. frondosa.(Fig. 11-14). Nesta última espécie, a ornamentação dos pólens só pôde ser definida por meio da MEV.

Medidas - As medidas dos diâmetros e demais caracteres quantitativos encontram-se nas Tab. 2,3 e 4. Em C. frondosa, estas medidas foram tomadas em grãos de pólen 4-aperturados (Fig. 8) por serem estes predominantes.

Nos materiais de comparação (Tab. 3), os dados obtidos revelam que apenas o exemplar. Silva 143 de C. yco apresenta as medidas dos diâmetros dos grãos de pólen compreendidas dentro das faixas de variação do material padrão. As medidas do diâmetro polar de C. flexuosa (exemplar Nascimento 15) e de C. yco (exemplar 

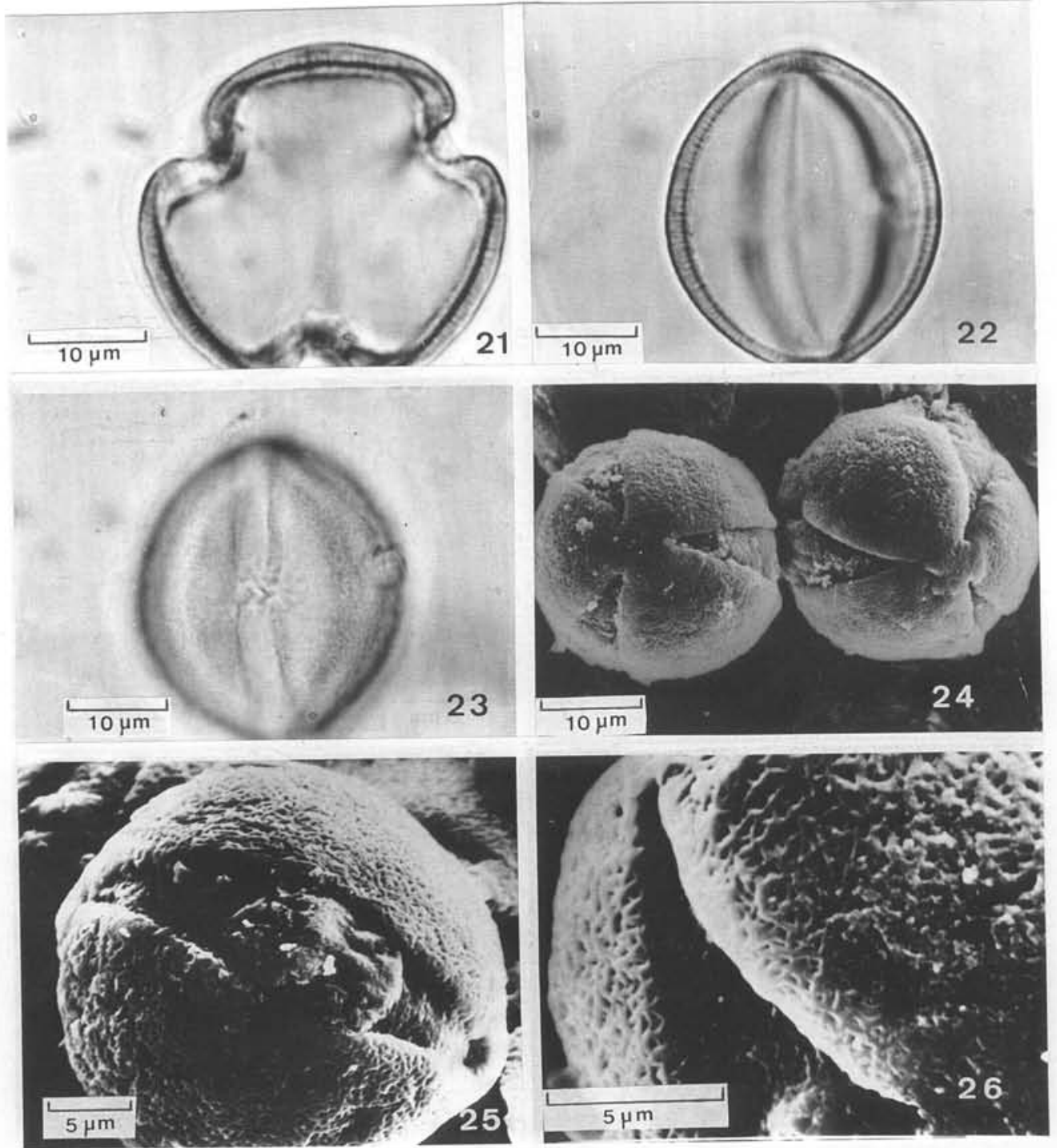

Figuras 21-26. Capparis yco. (Mart.) Eichler. 21. Fotomicrografia do pólen em vista polar mostrando o contorno e corte óptico; 22. Vista equatorial; 23. Detalhe da abertura; 24 . Elétron-micrografia do grão de pólen em vista polar; 25. Detalhe do cólporo; 26 . Detalhe da superfície do pólen.

Sales 340), também se enquadram dentro da faixa de variação dos respectivos materiais padrões. Quanto aos caracteres qualitativos, todos os espécimes de comparação confirmaram os resultados obtidos nos respectivos materiais padrões.

Chave polínica para as espécies estudadas de Capparis
1. Grãos de pólen com exina reticulada; âmbito subtriangular ou subcircular-lobado

2. retículos com lúmens de tamanhos desiguais, visíveis ao microscópio de luz, âmbito subcircular-lobado.

C. jacobinae

2. retículos com lúmens pequenos e desiguais, visíveis apenas ao MEV; âmbito subtriangular C. yco

1. Grãos de pólen com exina espinhosa; âmbito subtriangular e/ou subcircular 
Tabela 2. Medidas dos diâmetros dos gräos de pólen de espécies de Capparis $(\mathrm{n}=25)$ em vistas equatorial (VE) e polar (P) Espécies diâmetro equatorial (VP)

\begin{tabular}{lc} 
C. flexuosa & Faixa de variação $(\mu \mathrm{m})$ \\
C. frondosa & $21,7-26,8$ \\
C. jacobinae & $24,0-27,5$ \\
C. yco & $30,6-34,4$ \\
& $38,9-46,7$ \\
C. flexuosa & $28,2-36,9$ \\
C. frondosa & $24,6-33,1$ \\
C. jacobinae & $36,8-41,4$ \\
C. yco & $45,4-57,3$ \\
C. flexuosa & $20,9-26,6$ \\
C. frondosa & $16,5-27,2$ \\
C. jacobinae & $29,9-34,9$ \\
C. yco & $39,3-46,9$ \\
\hline
\end{tabular}

$x+\operatorname{sx}(\mu \mathrm{m})$

Tabela 3. Média aritmética das medidas dos grãos de pólen dos materiais de comparação de espécies de Capparis (n=10).

\begin{tabular}{|c|c|c|c|c|}
\hline \multirow[t]{2}{*}{ Espécies } & \multicolumn{2}{|c|}{ vista equatorial $(\mu \mathrm{m})$} & \multirow{2}{*}{$\begin{array}{l}\text { vista polar }(\mu \mathrm{m}) \\
\text { diâm. equatorial }\end{array}$} & \multirow[t]{2}{*}{$\mathrm{P} / \mathrm{E}$} \\
\hline & diâm. polar & diâm. equatorial & & \\
\hline (Nascimento 29) & 34,7 & 27,3 & 29,6 & subprolato \\
\hline (Laurênio et al. 259) & 39,8 & 33,6 & 33,1 & subprolato \\
\hline \multicolumn{5}{|l|}{ C. jacobinae } \\
\hline (Figueiredo 227) & 33,7 & 24,6 & 25,0 & prolato \\
\hline (Nascimento 15) & 37,1 & 29,5 & 28,6 & subprolato \\
\hline \multicolumn{5}{|l|}{ C. yco } \\
\hline (Sales 340) & 55,9 & 44,9 & 47,6 & subprolato \\
\hline (Silva 143) & 52,1 & 39,4 & 42,4 & subprolato \\
\hline
\end{tabular}

Tabela 4. Média aritmética das medidas das aberturas e da espessura da exina dos grãos de pólen de espécies de Capparis ( $\mathrm{n}=10$ ).

\begin{tabular}{lccccc}
\hline Espécies & \multicolumn{2}{c}{ colpo $(\mu \mathrm{m})$} & \multicolumn{3}{c}{ espessura da exina $(\mu \mathrm{m})$} \\
\hline & compr. & larg. & exina & sexina & $\mathrm{n}$ exina \\
C. flexuosa & 22,5 & 1,4 & 2,0 & 1,3 & 0,7 \\
C. jacobinae & 31,6 & 3,0 & 3,0 & 1,8 & 1,3 \\
C. yco & 41,8 & 5,6 & 3,6 & 2,7 & 0,9 \\
C. frondosa & - & - & 1,6 & 0,9 & 0,7 \\
\hline
\end{tabular}

3. com espinhos nítidos de pontas arredondadas e tamanhos variáveis; âmbito subtriangular C. flexuosa

3. com espinhos pequenos (espículos), de tamanhos diferentes, visíveis somente ao MEV; âmbito subtriangular (3-colporado) e subcircular (4-colporado) C. frondosa

\section{Discussão}

Os grãos de pólen das espécies estudadas tiveram regularidade quanto à forma, variando caracteristicamente pela escultura da exina. Ao microscópio óptico, os grãos de pólen de todas as espécies pareciam apresentar a exina reticulada, no entanto, ao serem observados ao MEV, pôdese constatar dois tipos: o espinhoso ou espiculoso, e o reticulado. Baseado principalmente nesta característica, foi possível a separação das espécies estudadas por meio de chave polínica.

Outra característica que permitiu distinguir as espécies de Capparis estudadas foi o tamanho dos grãos de pólen. Pela análise do intervalo de 
confiança (IC) a $95 \%$ dos diâmentros dos grãos de pólen só não foi possível separar significativamente $C$. flexuosa de $C$. frondosa, levando-se em conta o diâmetro polar em vista equatorial (Tab. 2). Gomes Jr. (1966) estudou os grãos de pólen de $C$. cynophallophora e $C$. yco, descrevendo-os como sendo 3-porados, com exina microrreticulada e diâmentro equatorial de $16,24 \mu \mathrm{m}$ na primeira, e $24,28 \mu \mathrm{m}$ na segunda. Tais resultados diferem dos aqui obtidos, principalmente quanto às aberturas, pois as quatro espécies estudadas apresentaram grãos de pólen 3-colporados ou (3)-4-colporados (em C. frondosa) e não porados, como observou Gomes Jr. (1966). Há também divergências na medida do diâmetro equatorial dos grãos de pólen de C. yco, onde os espécimes aqui estudados apresentaram medidas bem maiores, concordando, porém, quanto à ornamentação microrreticulada. Devese, entretanto, salientar que a metodologia utilizada por Gomes Jr. (1966) na preparação dos grãos de pólen não destrói o conteúdo polínico como ocorre com a acetólise, o que dificulta as observações, surgindo daí, provavelmente, as divergências citadas.

Gonçalves-Esteves \& Ferreira (1994), no estudo polínico das espécies de Capparaceae de restinga do Estado do Rio de Janeiro, descreveram os grãos de pólen de três espécies de Capparis, incluindo $C$. flexuosa, como sendo de tamanho médio, isopolares, prolato-esferoidais, 3-colporados, âmbito subcircular e exina reticulada. Os dados polínicos obtidos no presente trabalho para $C$. flexuosa diferem dos mencionados autores quanto à escultura da exina que é espinhosa, mas referida por eles como reticulada. Estas diferenças foram confirmadas nos materiais de comparação e, portanto, é possível que o espécime estudado pelos autores acima citados apresente problemas de identificação botânica.

A espécie $C$. frondosa foi também estudada palinologicamente por Roubik \& Moreno (1991) e as descrições dos grãos de pólen concordam com as do espécime aqui estudado na maioria dos caracteres polínicos, exceto quanto à escultura que, segundo estes autores, é escabrada e não espiculosa como observado no presente trabalho.
Entretanto, esta diferença só foi possível ser estabelecida em MEV.

Duas outras espécies de Capparis ( $C$. formosana Hemsl. e C. membranacea Gard. \& Champ. var. angustissima Hemsl.), foram estudadas por Huang (1972), apresentando grãos

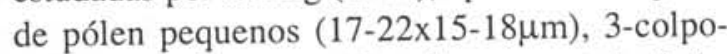
rados, subprolatos e exina finamente reticulada, características em parte concordantes com as das espécies aqui descritas.

Segundo Costa e Silva (1995), C. jacobinae e C. yco, embora habitem o mesmo ambiente, as caatingas nordestinas, são distintas quanto aos caracteres vegetativos, tendo sido colocadas por Eichler (1865) em seções diferentes. A morfologia polínica destas espécies confirma em parte este posicionamento, pois apesar de terem o mesmo tipo polínico de escultura (reticulado), os grãos de pólen são distintos quanto ao âmbito (subcircular-lobado em C. yco, e subtriangular em $C$. jacobinae $)$, tamanho $(39,1 \times 32,9 \mu \mathrm{m}$ em $C$. jacobinae e $51,0 \times 42,5 \mu \mathrm{m}$ em $C$. yco) e no padrão reticulado da exina, (com retículos quase imperceptíveis ao microscópio de luz, em C. yco).

Por outro lado, C. jacobinae e C. yco são palinologicamente distintas de $C$. flexuosa e $C$. frondosa no que se refere ao padrão de escultura. As duas espécies possuem exina espinhosa com espinhos nítidos em $C$. flexuosa, e espinhos pequenos, observáveis apenas em $\mathrm{MEV}$, em $C$. frondosa. Esta última mostrou maior diversidade polínica pois, além dos grãos de pólen com três e quatro aberturas, apresentou um tipo especial, com faces polares diferentes, devido, provavelmente, à especiação que estaria ocorrendo com a espécie estudada coletada na Ilha de Fernando de Noronha, face à impossibilidade de entrecruzamento com indivíduos do continente (Costa e Silva 1995). Entretanto, estes dados só poderão ser confirmados futuramente, estudando-se os grãos de pólen de outras exsicatas coletadas na Ilha e no continente.

Considerando-se as espécies de Capparis estudadas no presente trabalho, a análise morfológica dos grãos de pólen revelou-se importante no auxílio das delimitações específicas. 


\section{Referências bibliográficas}

Barroso, G. M.; Guimarães, E. F.; Ichaso, C. L. F.; Costa, C. G. \& Peixoto, A. L. 1978. Sistemática de Angiospermas do Brasil, v.1. EDUSP, São Paulo

Barth, O. M. \& Melhem, T. S. 1988. Glossário ilustrado de Palinologia. UNICAMP Ed., Campinas.

Costa e Silva, M. B. 1995. Estudos taxonômicos sobre o gênero Capparis L. (Capparaceae Juss.) em Pernambuco-Brasil. Dissertação de Mestrado. Universidade Federal de Pernambuco, Recife.

Eichler, A. 1865. Capparidaceae. In: C.F.P. von Martius (Ed.), Flora Brasiliensis, v.13, n.1.

Erdtman, G. 1960. The acetolysis method. A revised description. Svensk Botanisk Tidskrift 39: 561-564.

Fonnegra, G. R. 1989. Métodos de estudo palinológico: microscopia electronica de barrido. Universidad de Antioquia, Medellin.

Gomes Jr., J. C. 1966. Contribuição ao conhecimento do pólen das plantas da caatinga. I. Arquivos de Botânica de São Paulo 4(2): 89-93.
Gonçalves-Esteves, V. \& Ferreira, B. C. 1994. Estudo polínico em plantas de restinga do Estado do Rio de Janeiro. Anacardiaceae Lindl. e Capparaceae Juss. Boletim do Museu Nacional 90: 1-13.

Huang, T. C. 1972. Pollen flora of Taiwan. National Taiwan University, Botany Department Press, Taiwan

Hutchinson, J. 1968. The genera of flowering plants: Angiospermae. Clarendon Press, Oxford.

Jacobs, M. 1960. Flora Malesiana 6(1): 61-105.

Punt, W.; Blackmore, S.; Nilsson, S. \& Le Thomas, A. 1994. Glossary of pollen and spore terminology. L. P. P. Foundation, Laboratory of Palaeobotany and Palynology, Utrecht, The Netherlands.

Roubik, D. W. \& Moreno, P. J. E. 1991. Pollen and spores of Barro Colorado Island. Monograph in Systematic Botany 36: 1-268.

Willis, J. C. 1980. A dictionary of the flowering plants and ferns. Cambridge University Press, Cambridge. 